\title{
Environmental Determinants of Coronavirus Disease 2019 (COVID-19)
}

\author{
Eric B. Brandt ${ }^{1} \cdot$ Tesfaye B. Mersha $^{1}$ (D) \\ Accepted: 26 January 2021 / Published online: 5 March 2021 \\ (C) The Author(s), under exclusive licence to Springer Science+Business Media, LLC part of Springer Nature 2021
}

\begin{abstract}
Purpose for Review Since the coronavirus SARS-CoV-2 outbreak in China in late 2019 turned into a global pandemic, numerous studies have reported associations between environmental factors, such as weather conditions and a range of air pollutants (particulate matter, nitrogen dioxide, ozone, etc.) and the first wave of COVID-19 cases. This review aims to offer a critical assessment of the role of environmental exposure risk factors on SARS-CoV-2 infections and COVID-19 disease severity.

Recent Findings In this review, we provide a critical assessment of COVID-19 risk factors, identify gaps in our knowledge (e.g., indoor air pollution), and discuss methodological challenges of association and causation and the impact lockdowns had on air quality. In addition, we will draw attention to ethnic and socioeconomic factors driving viral transmission related to COVID-19. The complex role angiotensin-converting enzyme 2 (ACE2) plays in COVID-19 and future promising avenues of research are discussed.

Summary To demonstrate causality, we stress the need for future epidemiologic studies integrating personal air pollution exposures, detailed clinical COVID-19 data, and a range of socioeconomic factors, as well as in vitro and in vivo mechanistic studies.
\end{abstract}

Keywords COVID-19 $\cdot$ SARS-CoV2 $\cdot$ Air pollution $\cdot$ Weather $\cdot$ Smoking

\section{Introduction}

Nearly a century after the 1918 influenza pandemic that killed an estimated 50 million people worldwide [1], 2019 saw the emergence in Wuhan, China, of a new coronavirus (2019nCov) causing severe respiratory symptoms, called coronavirus disease 2019 (COVID-19) [2, 3]. Its sequence homology with the coronavirus causing the acute respiratory syndrome (SARS-CoV) in 2003 leads to the adoption of its present name: SARS-CoV-2 [2]. As this new coronavirus quickly spread across the world, the World Health Organization (WHO) declared SARS-Cov-2 a public health emergency on January 30, 2020, and a global pandemic on March 11, 2020.

This article is part of the Topical Collection on Allergies and the Environment

Tesfaye B. Mersha tesfaye.mersha@cchmc.org

1 Cincinnati Children's Hospital Medical Center, University of Cincinnati, 3333 Burnet Avenue, MLC 7037,

Cincinnati, OH 45229-3026, USA
As of November 2020, the United States is leading the world in number of SARS-CoV-2 positive cases (> 11 million) and COVID-19-associated death ( $>245,000)$ [4], largely surpassing the cumulative deaths attributed to influenza over the last 5 years (https://www.cdc.gov/flu/about/burden/past-seasons.html). Worldwide, over 55 million cases and 1.3 million death is attributed to COVID-19, numbers that are likely undercounted and will unfortunately rise over the coming winter months.

\section{Epidemiology and Clinical Features of COVID-19}

Like many respiratory viruses, SARS-CoV-2 is transmitted by close contact, notably via small respiratory droplets emitted when people sneeze, cough, and to a lesser extent speak. Early reports out of China highlighted that elderly people, notably men with underlying health conditions, were at high risk of hospitalization and death [5]. Indeed, the fatality rate among people over 70 years of age diagnosed with COVID-19 was well above $10 \%$ but was $0.1 \%$ for children and young adults [6]. While rare, cases of severe or fatal COVID-19 do occur in 
adolescents and young individuals in their twenties [7, 8], suggesting either an undiagnosed underlying health condition and/or potential genetic and gene-environment interactions. A growing list of potential gene polymorphisms conferring increased susceptibility to severe COVID-19 is being reported [9]. Unsurprisingly, some of these life-threatening polymorphisms impair antiviral responses by affecting type 1 IFN signaling $[10,11]$. Future research might uncover geneenvironment interactions between candidate genes like these and air pollutants. However, gene-environment studies have their challenges, notably inadequate sample size/power, extensive computational demand, and the burden of multiple testing $[12,13]$.

The aforementioned underlying health conditions reported to increase the risk of developing severe or fatal COVID-19 include obesity; diabetes; hypertension; cardiovascular diseases; heart, kidney, and liver diseases; immunodeficiencies (cancers, transplants, etc.); and chronic obstructive pulmonary disease (COPD) (Fig. 1) [14, 15]. Interestingly, most early reports from the first wave of the pandemic found a low prevalence of asthma among patients with severe COVID-19 [16]. However, a large population-based study with almost half a million participants (UK Biobank) found asthmatics, notably those with non-allergic asthma, were at increased risk of developing severe COVID-19 [17]. It has been proposed that patients suffering from non-type 2 asthma, some of which have comorbidities like obesity or COPD, are at a higher risk for progression to severe COVID-19 [18]. A recent comprehensive review of COVID-19 risk factors can be found here [14].
Advanced age ( $>80$ years) is by far the major risk factor for fatal COVID-19 [5, 19]. Other demographic risk factors include male sex, race, and socioeconomic status (Fig. 1) [19, 20]. Indeed, racial minorities and people of low socioeconomic status in general represent an outsized portion of COVID-19 deaths [21-24]. Among 2658 SARS-CoV-2-tested UK Biobank participants, low socioeconomic status was associated with a higher risk of confirmed infection (risk ratio 2.19; 95\% CI 1.80-2.66 for most deprived quartile vs least) [25]. Individuals of Black race (RR 3.35; 95\% CI 2.48-4.53) or Pakistani ethnicity (RR 3.24; 95\% CI 1.73-6.07) were at increased risk for COVID-19-related hospitalization compared to White British even after accounting for socioeconomic variables (RR 2.05; 95\% CI 1.39-3.03) [25]. In a retrospective cohort study in Louisiana, Blacks were overrepresented among all patients who died in the hospital (70.6\%) [26]. However, Black race was not associated with higher inhospital mortality than White race, after adjusting for differences in sociodemographic characteristics [26]. Similarly, in a US cohort study of 11,210 adult patients from 12 states hospitalized with COVID-19, there was no statistically significant difference in risk of mortality between Black and White hospitalized patients after adjustment for age, sex, insurance, comorbidities, neighborhood deprivation, and site of care [27]. Nevertheless, in Louisiana, Black individuals were at increased risk of being hospitalized compared to Whites (OR $1.96 ; 95 \%$ CI 1.62-2.37) [26]. Taken together, these findings suggest that socioeconomically deprived racial minorities are at increased risk of infection by SARS-CoV-2, likely for a range of reasons including crowded living conditions and

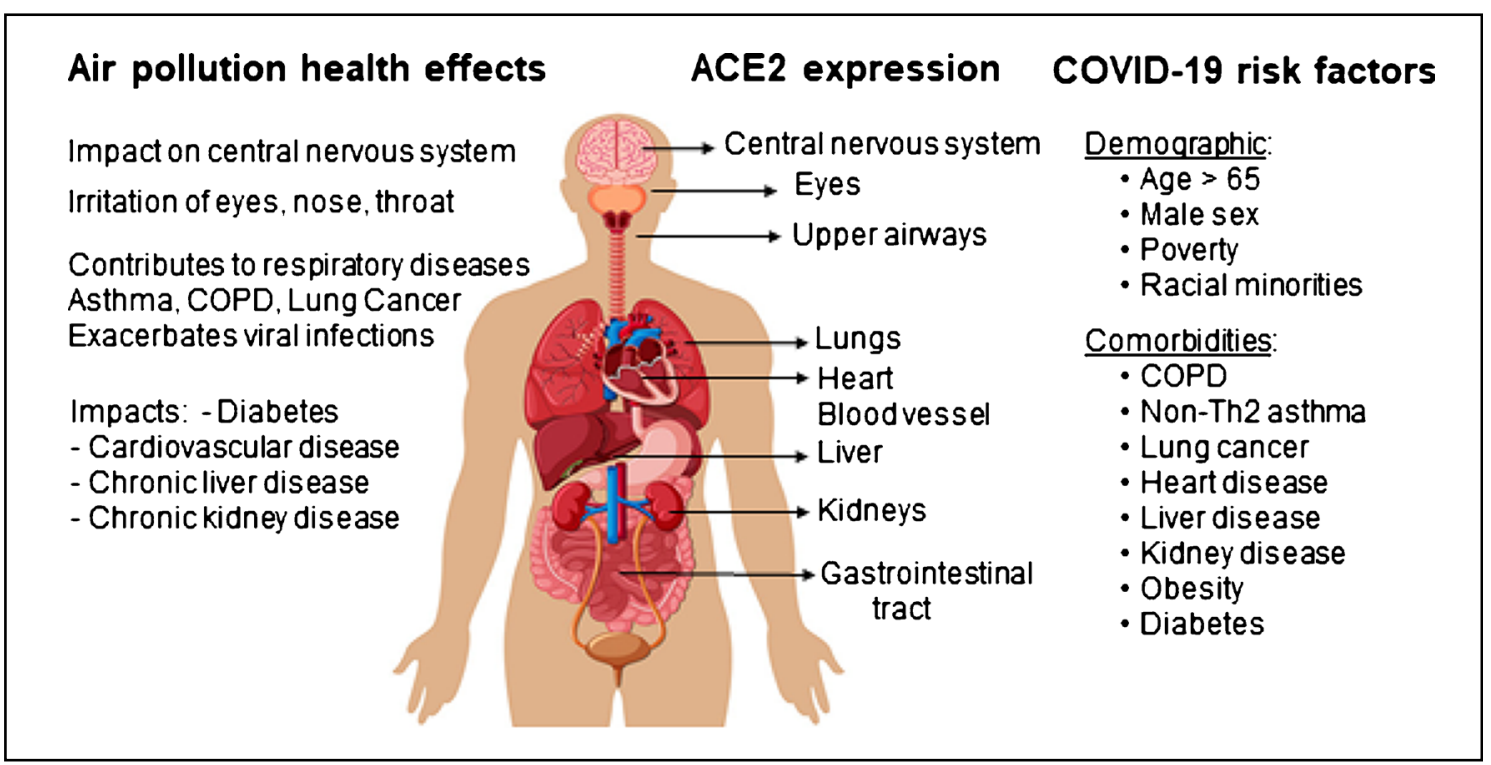

Fig. 1 Air pollution's impact on health exacerbates COVID-19. Chronic exposure to air pollution contributes to adverse health outcomes associated with a range of chronic diseases most of which overlap with risk factors for severe COVID-19. The receptor for SARS-CoV-2, angiotensin-converting enzyme 2 (ACE2), is expressed in numerous organs explaining the wide range of symptoms associated with COVID-19 
being essential workers during the lockdown [21, 23, 24]. While growing evidence support an association between vitamin D deficiency and adverse COVID-19 outcomes [28], its contribution to the increased risk faced by individuals with dark skin with low vitamin D requires further investigation.

\section{Environmental Factors Affecting COVID-19 Cases and Outcomes}

While a wide range of environmental factors may contribute to SARS-CoV-2 transmission and COVID-19 severity, published studies so far have mainly focused on air pollution and weather conditions. We will therefore present here a comprehensive overview as well a critical assessment of the most relevant of this rapidly growing list of peer-reviewed publications investigating association between air pollution and COVID-19 outcomes. We will discuss challenges in conducting these studies, most of which are ecological in nature and limitations in their interpretation.

\section{Air Pollution, Mortality, Health Disparities, and Chronic Diseases}

The impact of air pollution on human health is supported by numerous epidemiologic studies worldwide and represents a significant contributor to the global burden of disease [29,30]. Air pollution is a complex mixture that includes, among others, small particulate matter $\left(\mathrm{PM}_{2.5}, \mathrm{PM}_{10}\right)$, nitric dioxide $\left(\mathrm{NO}_{2}\right), \mathrm{SO}_{2}, \mathrm{CO}$, and volatile organic compounds (VOCs) derived from vehicular traffic, industry, and household emissions. The majority of large cohorts around the world found a significant increased risk of mortality per $10 \mu \mathrm{g} / \mathrm{m}^{3}$ increase in $\mathrm{PM}_{2.5}$ exposure [31]. Increased air pollution-associated mortality is not only observed in developing countries in Africa and Asia [30], but also in the United States despite much stricter air quality standards [32]. Specifically, a $10 \mu \mathrm{g} / \mathrm{m}^{3}$ increase in long-term $\mathrm{PM}_{2.5}$ exposure is associated with a $7.3 \%$ (hazard ratio 1.073; 95\% CI 1.071-1.075) increase in the rate of all mortality causes. Among Blacks, the estimate for $\mathrm{PM}_{2.5}$ was three times as high as that for the overall population [32]. Indeed, pollution-associated health effects disproportionally affect low-income families and racial minorities in the United States [33].

Fine and ultrafine particles (particles smaller than, respectively, 2.5 and $0.1 \mu \mathrm{m}$ in diameter) can reach the alveoli and cross into not only the blood stream but may also cross the brain barrier or reach the fetus, potentially contributing to low infant birth weights $[34,35]$. Thus, air pollution does not only promote oxidative stress in the airways [36], it also leads to an accumulation of particles throughout the body over a lifetime. Accordingly, exposure to air pollutants has been associated with not only acute respiratory illnesses but also with a wide range of chronic diseases like cardiovascular diseases, diabetes, cancers, and chronic liver and kidney diseases [30], most of which overlap with risk factors for severe COVID-19 (Fig. 1). Air pollution can negatively influence lung development in children and adolescents [37]. However, the greatest pollution-related deleterious impacts may occur later in life, since reduced lung function is a strong risk factor for complications and early death during adulthood [38]. Besides its reported impact on COPD and asthma [39, 40], air pollution has also been shown to promote respiratory viral infections, recently reviewed here [41]. Notably, in a large observational case-crossover study, short-term increases in $\mathrm{PM}_{2.5}$ were associated with elevated odds of being diagnosed with RSV in young children or influenza in children of all ages [42]. Importantly, three studies assessing the impact of air pollution on the SARS outbreak in the spring of 2003 in China reported positive associations [43-45]. Specifically, each $10 \mu \mathrm{g} / \mathrm{m}^{3}$ increase over a 5-day moving average of $\mathrm{PM}_{10}$ and $\mathrm{NO}_{2}$ corresponded to a relative risk increase of, respectively, 1.06 (95\% CI 1.00-1.12) and 1.22 (95\% CI 1.01-1.48) [44]. However, meteorological factors appear to show a stronger association than air pollution index in the third study [45]. A critical review of these studies and their limitations can be found here [46].

\section{Weather Conditions Affect Air Pollution and COVID-19 Cases}

Viral infections often increase during the winter season. The rise in the cases is thought to be due to the effect of the environment on viral stability, transmission, behavior changes of humans where colder temperatures restrict outdoor activities in favor of indoor gatherings, and changes in immunity level $[47,48]$. Winter months are usually associated with lower temperatures, lower absolute humidity, and lower indoor relative humidity. The first wave of the pandemic affected countries in the Northern hemisphere (China, Europe, and the United States) during the winter and early spring months. There is evidence that SARS-CoV-2 survives longer on surfaces in temperate rather than warm conditions [49]. COVID19 cases have been substantially lower in tropical countries, potentially in part because of higher temperature [50]. Indeed, several studies have found modest but significant associations between weather conditions, notably humidity and temperature, and COVID-19 cases [51-54]. However, other studies have not always found significant associations between meteorological factors and COVID-19 cases [55]. Anecdotally, while COVID-19 cases substantially decreased during the summer months in Europe following spring lockdowns and continuous social distancing measures, COVID-19 cases increased over the summer months in some US states like Florida where usage of air conditioning is ubiquitous, suggesting that outdoor temperatures may not be a critical factor in 
SARS-CoV-2 transmission. Indeed, the potential impact of climate and weather conditions on SARS-CoV-2 transmission is likely minor when placed in the context of mitigation strategies and lack of population immunity during a pandemic and should not adversely shape risk perception [54, 56, 57]. A framework to improve research vying to link weather, climate, and COVID-19 has been proposed [58]. Finally, it is also important to note that weather conditions also directly impact air pollution [59], and this should be taken into account when trying to assess the respective contribution of weather conditions and air pollution on COVID-19.

\section{Impact of Lockdowns on Air Pollution}

In the early days of the pandemic, numerous affected countries have resorted to mitigation strategies involving some form of home isolation to curb the spread of the virus [60-63]. Because long-term exposure studies often use average yearly exposure measurements from prior years, the long-term studies mentioned above won't take into account variation in pollution exposure following total lockdowns of whole regions or countries. These shelter-in-place lockdowns have resulted in significant decreases in traffic-related air pollution, especially in the most highly polluted areas in China, India, Brazil, Italy, and the United States [64-66]. Of note, in New York City where air pollution is severalfold lower than in Wuhan or Delhi, the observed reduction in $\mathrm{NO}_{2}$ and $\mathrm{PM}_{2.5}$ levels observed in early spring of 2020 was similar in magnitude to seasonal declines were observed in the previous 5 years [66]. Finally, several studies have now reported that this decrease in traffic-related air pollution during regional lockdowns was associated with a significant increase in ozone $[64,65,67]$ as well as, in China at least, fine particulate matter $[64,68]$. These changes in the nature of air pollutants during the first wave of the SARS-CoV-2 pandemic highlight the challenges in assessing the potential impact of air pollution on COVID-19 outcomes. They also offer opportunities to improve mathematical modeling of the impact that these dramatic reductions in traffic-related air pollution will have on overall pollution levels in cities around the world. Estimating the benefit from this transient decrease in traffic-related air pollution on SARS-CoV-2 spread in light of the mitigation strategies designed to curb the spread of the virus is even more challenging.

\section{Assessing the Impact of Air Pollution on the First Wave of the Pandemic}

As soon as the first wave of COVID-19 cases exploded in China and Italy in early 2020, several reports noticed an association between highly polluted regions, like the Po Valley in Italy, and large numbers of COVID-19 cases. Within a month, a string of studies of varying quality started to appear in preprint on medRxiv. A couple of summaries of these early studies have been published [46, 69].

Before we highlight a few studies from China, Europe, and the United States, it is important to acknowledge that these early studies are ecological in nature. This means that the data used in these studies rely on publicly available air pollution data and COVID-19 cases within administrative regions and offer no insight into individual exposures or health outcomes. A portion of these early studies are long-term exposure studies, which assess the chronic impact of air pollutants on disease outcomes, often using annual mean levels of certain pollutants $\left(\mathrm{NO}_{2}, \mathrm{PM}_{2.5}\right.$, etc.) during prior years. Thus, long-term exposure studies are a reflection of the impact that years of exposure to air pollution have on a range of chronic diseases representing risk factors for severe COVID-19. In contrast, short-term studies use time-series to determine the effects of short-term changes in air pollution on health outcomes [70], by modeling potential associations between daily variations in both air pollution and, for example, COVID-19 mortality.

In a short-term exposure study conducted in 120 Chinese cities between January 23 and February 29, 2020, Zhu et al. found a positive association between daily concentrations of $\mathrm{PM}_{2.5}, \mathrm{PM}_{10}, \mathrm{NO}_{2}, \mathrm{O}_{3}$, and to a lesser degree $\mathrm{CO}$ with daily confirmed COVID-19 cases [71]. All air pollutants significantly correlated with each other and with average daily temperatures and humidity. To reduce collinearity, the author assessed each pollutant separately, while controlling for weather (temperature, humidity, air pressure, wind speed) and time-independent fixed effects, like city size and population density. As the incubation period for SARS-CoV-2 is $3-$ 14 days, the authors estimated the association between COVID-19 cases and moving average concentrations of air pollutant (lag0-7, lag0-14, lag0-21) using a generalized additive model (GAM) and assumed a Gaussian distribution. Specifically, a $10 \mu \mathrm{g} / \mathrm{m}^{3}$ increase (lag0-14) in $\mathrm{PM}_{2.5}, \mathrm{PM}_{10}$, $\mathrm{NO}_{2}$, and $\mathrm{O}_{3}$ were associated with, respectively, a $2.24 \%$, $1.76 \%, 6.94 \%$ and $4.76 \%$ increase in COVID-19 cases. Of note, $\mathrm{SO}_{2}$ showed an inverse association. Overall results were generally similar if the city of Wuhan, which had significantly more cases, was excluded from the analysis or when the authors used a two-pollution model. Findings for particulate matter were confirmed by another short-term study excluding the city of Wuhan but including 63 cities ( 37 with $>100$ cases and 26 with 50-100 cases) [72]. The small number of confirmed COVID-19 cases outside the city of Wuhan and the use of regression models assuming normal distribution temper these findings [46].

A long-term study in the United States used COVID-19 death counts reported in 3089 US counties between March 22 and June 18, 2020, and average $\mathrm{PM}_{2.5}$ concentrations (2000-2016) for each county based on calculated estimates combining satellite data, chemical transport models, and ground monitors [73]. Of note, during this first wave of 
the pandemic, the majority of less-populated central states reported few cases and as a result about $40 \%$ of US counties had no COVID-19 deaths as of June 18. The authors therefore used a negative binomial mixed regression model and also conducted numerous sensitivity analyses to assess the robustness of their findings. The authors found that an increase of 1 $\mu \mathrm{g} / \mathrm{m}^{3}$ in long-term average PM2.5 is associated with a significant $11 \%$ (mortality rate ratio $1.11 ; 95 \%$ CI $1.06-1.17$ ) increase in COVID-19 mortality rate [73]. Other significant confounding associations with COVID-19 mortality included population density, median household income, education (less than high school degree), smoking, and age ( $>65$ years). The strength of the association between $\mathrm{PM}_{2.5}$ and COVID-19 mortality remained largely unchanged when the city of New York, which experienced a large number of COVID-19 deaths, were excluded. The authors highlight the strength and limitations (no adjustment for individual-level risk; potential outcome errors; no real-time exposures) of their study in a detailed table [73]. A similar study focused on hazardous pollutants also found that a $1 \mu \mathrm{g} / \mathrm{m}^{3}$ increase in PM2.5 correlated with a 7\% (MRR 1.07; 95\% CI 1.02-1.12) increase in COVID-19 mortality rate ratio [74]. However, while positive associations with diesel PM and acetaldehyde hazard quotients remained significant in a multi-pollution model, $\mathrm{PM}_{2.5}$ did not. Similarly, in another cross-sectional nationwide study using zero-inflated negative binomial models to estimate the association between long-term (2010-2016) county-level exposures to $\mathrm{NO}_{2}, \mathrm{PM}_{2.5}$, and ozone and COVID-19 case-fatality and mortality rates, $\mathrm{PM}_{2.5}$ was significantly associated with COVID-19 mortality rates when a single pollutant model was used but was barely significant (MRR 1.15 ; $95 \%$ CI 1.00 $1.32 ; p=0.051$ ) in a tri-pollutant model, whereas $\mathrm{NO}_{2}$ levels remained positively associated with both COVID-19 case-fatality and mortality rates [75]. Although the authors controlled for several confounders including weather conditions; demographic, socioeconomic, and health-related factors; and population density, they could not exclude that $\mathrm{NO}_{2}$ may be a proxy for urbanicity [75].

The long-term study by Travaglio et al. is the first published study to employ individual-level data obtained by the UK Biobank to assess the relationship between air pollution exposure and COVID-19, after controlling for individual confounders such as age, socioeconomic status, and underlying health conditions [76]. This dataset contained 1464 participants who had been tested by April 26, 2020, including 664 diagnosed with COVID-19. Long-term average (2014-2018) exposure to $\mathrm{PM}_{2.5}, \mathrm{PM}_{10}$, and $\mathrm{NO}_{2}$ were significantly associated with increased COVID-19 cases. Specifically, a 1-unit increase in $\mathrm{PM}_{2.5}, \mathrm{PM}_{10}$, and $\mathrm{NO}_{2}$ were associated with, respectively, a $12 \%, 8 \%$, and $4.5 \%$ increase in cases [76]. In contrast, their ecological study using local-level data $(103,409$ lab-confirmed COVID-19 cases and 32,903 deaths reported in England between February 1 and end of April 2020) suggests that while a $1 \mu \mathrm{g} / \mathrm{m}^{3}$ increase in $\mathrm{NO}_{2}$ is associated with little over 3\% more cases and COVID-19-related deaths, $\mathrm{PM}_{2.5}$, $\mathrm{PM}_{10}$, and ozone are negatively associated with infections and COVID-19 mortality [76]. This discrepancy likely reflects ecological bias, notably when assessing exposure levels, as the Biobank participant exposure was estimated based on the nearest available air pollution measures. Taken together, while these studies support a role for air pollution in promoting COVID-19, more detailed studies covering multiple waves of SARS-CoV-2 infections and including more personalized data are needed to confirm these findings.

\section{Potential Contribution of Particulate Matter to Airborne SARS-CoV-2 Transmission}

SARS-CoV-2 has been proposed to not only be carried by respiratory droplets but also by smaller airborne particles (droplet nuclei $<5 \mu \mathrm{m}$ ) that can stay in the air for hours and travel longer distances [77-79]. Airborne SARS-CoV-2 RNA has been detected indoors in two Wuhan hospitals and in crowded areas nearby [80]. However, more studies are needed to assess to what degree airborne SARS-CoV-2 transmission occurs indoors, not only in a hospital setting but also in households where poor indoor air quality may promote viral transmission. The potential contribution of particulate matter to outdoor SARS-CoV-2 transmission was raised by a study where a quarter of the $34 \mathrm{PM}_{10}$ samples collected from outdoor air samplers in the Italian City of Bergamo had detectable SARS-CoV-2 RNA [81]. Another study collected particulate matter from Venice in northern Italy and Lecce, in the south, and found concentrations of virus-laden aerosol $\mathrm{PM}_{10}$ samples below 0.8 copies $/ \mathrm{m}^{3}$ [82]. These low concentrations are unlikely to represent a major vector of transmission for SARSCoV-2 in outdoor settings, at least at these levels of pollution and SARS-CoV-2 reported cases.

\section{Indoor Air Pollution and COVID-19}

In addition to some outdoor pollutants, indoor air contains a range of pollutants, including VOCs from furniture and household products [83, 84] (https://www.epa.gov/indoor-airquality-iaq/what-are-volatile-organic-compounds-vocs). Exposure to indoor air pollution from household energy use depends on type of fuel, housing characteristics, and stove use behavior. In developing countries, fumes from burning biomass (wood) for heating and cooking are a major source of indoor air pollution and contribute to respiratory infections $[85,86]$. Exposure to smoke from biomass burning is reported to promote COPD [86, 87]. However, in a recent large population-based study (Burden of Obstructive Lung Disease), which included 18,554 adults from low-/middleand high-income countries, airflow obstruction was not associated with self-reported use of solid fuels for cooking or 
heating [88]. Thus rigorous studies will be needed to determine if, as suggested [89], biomass burning might also impact COVID-19. Early studies suggest that a history of smoking and/or COPD increases the risk of developing severe COVID$19[5,15,90]$. The role of current smoking is not yet clear [ 90 , 91]. In the British OpenSAFELY study, which included 10,926 COVID-19-related death, hazard ratios for former smokers were substantially higher than current smokers and remained high (HR 1.19; 95\% CI 1.14-1.24) after taking into account a range of confounding factors [19]. Thus, the irreversible decline in lung function following years of smoking is driving risk rather than current smoking status. There is limited information on the impact of secondhand smoke exposure on airway infections [92] and to our knowledge none regarding SARS-CoV-2. As mitigation strategies to limit the spread of this coronavirus have shifted the way people work and dramatically increased time spent indoors, more research on household and workplace air quality and its impact on health in general, and COVID-19 in particular, is urgently needed.

\section{In Search of a Causal Link Between Air Pollution and COVID-19 Severity}

\section{The Challenge of Determining Causality in Epidemiology}

It is important to distinguish between association and causation. Epidemiologists strive to conclude about causation, but most epidemiologic studies focus on establishing associations. Association is a statistical relationship between two variables, which may be associated without a causal relationship. Hence, correlation doesn't necessarily mean causation especially when numerous potential confounders are not assessed. Well-planned study design and analysis methods are part of the standard methodologic toolkit to determine causality in epidemiology. An excellent review of causal modeling methods used to assess the effects of environmental exposures like air pollution on health outcomes were recently published [93]. Because observational studies are not randomized, groups need to be as comparable as possible and significant results from these studies should always be interpreted with caution because of potential collider bias. For example, patients hospitalized with COVID-19 or volunteers participating in a large study like the UK Biobank may not be representative of the general population [94]. Bias and the use of incorrect parametric model specifications are limitations of causal inference. Using a cohort of 68 million Medicare enrollees and mathematical estimates of $\mathrm{PM}_{2.5}$ levels at the ZIP code levels, $\mathrm{Wu}$ et al. used both traditional regression modeling as well as three approaches for causal inference that rely on the potential outcomes framework and generalized propensity scores (GPSs) [95]. These approaches adjust for confounding using (i) matching by GPS, (ii) weighting by GPS, and (iii) adjustment by GPS, by including GPS as a covariate in the health outcome model. While traditional approaches rely on regression modeling to account for confounding factors, there is a need for individualized pollution assessment and large-scale testing for SARS-CoV-2 infections to identify all asymptomatic cases. In addition, current approaches are based on average regional value and there is a need of high-sensitivity wearable devices to monitor personal airborne biological and chemical exposures. The development of personalized air pollution monitors coupled with GPS tracking and the ability of smartwatches/health trackers to offer early warning of potential SARS-CoV-2 infection promises more personal risk assessments [96, 97]. Ultimately, personalized exposure measurements could be integrated with detailed personal health data resulting from the growing use of multi-omics most notably in COVID-19 patients.

\section{Potential Mechanisms: ACE2 Friend or Foe?}

Within months of its discovery, scientists established that like SARS-CoV [98], SARS-CoV2 infects cells through binding its spike glycoprotein to the angiotensin-converting enzyme 2 receptor (ACE2) following priming by transmembrane protease serine 2 (TMPRSS2) (Fig. 2) and/or other host proteases (furin, cathepsin, etc.) [99-101]. The presence of ACE2 on a wide array of cell types, across numerous organs (lung, heart, intestine, etc.), help explain the wide range of symptoms associated with COVID-19 (Fig. 1) [102].

Elevated ACE2 expression on epithelial cells, combined with the high affinity of the SARS-CoV-2 spike protein for ACE2 promotes viral infection in vitro $[99,100]$. The fact that ACE2 expression levels in the airway increase with age is only one potential reason young children have milder COVID-19 symptoms [8]. The hypothesis that severe COVID-19 cases might result from higher tissue levels of ACE2, increased infection and ultimately greater viral load is being actively investigated. Others have proposed that SARS-CoV-2 interaction with ACE2 leads to decreased ACE2 surface expression and impaired cardiopulmonary protection [103]. By converting angiotensin (Ang) I and II into Ang1-9 and Ang1-7, respectively, ACE2 acts as a regulator of the renin-angiotensin system [102], limiting vasoconstriction and pulmonary injuries (Fig. 2). In animal models of acute lung injury, ACE converts Ang I into Ang II driving severe lung failure via its receptor, whereas ACE2 generation of Ang1-9 and Ang1-7 act through their receptor to limit lung injury $[104,105]$. Consistent with its protective role in the lung, elevated pulmonary expression of ACE2 has been reported in smokers and in COPD patients [101, 106-108]. Pulmonary exposure of mice to $\mathrm{PM}_{2.5}$ for 3 consecutive days 


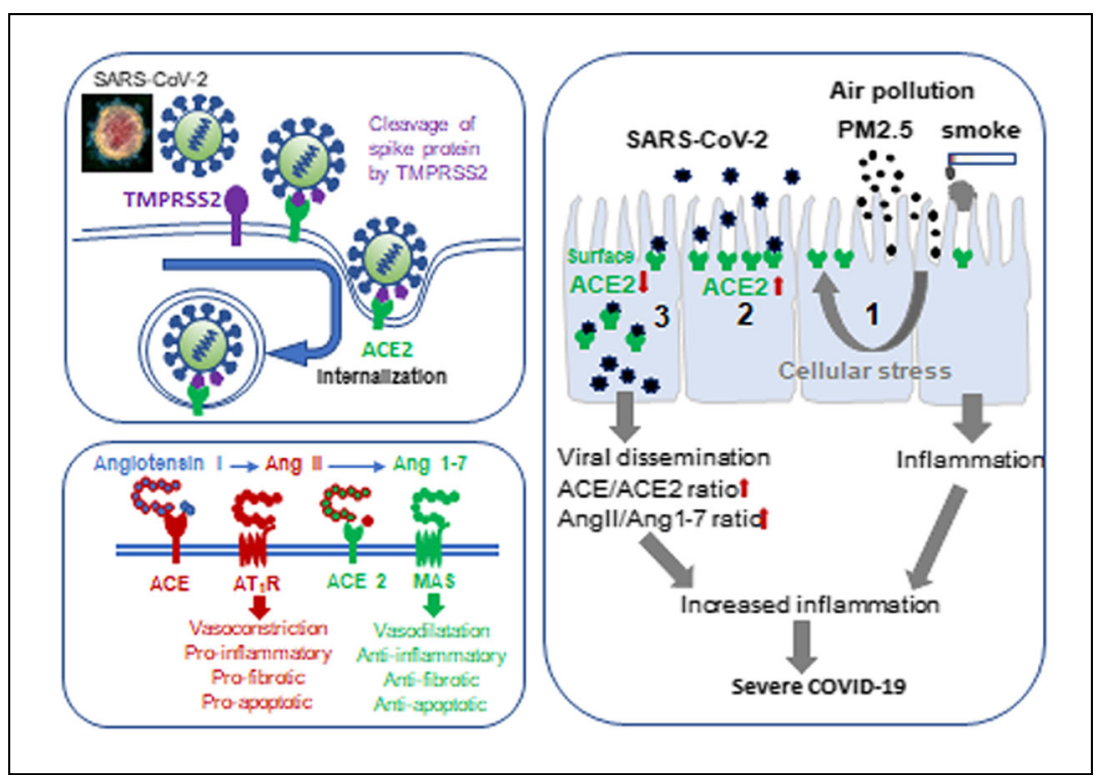

Fig. 2 The central role of ACE 2 in SARS-CoV-2 infection and COVID19 severity. Exposure to air pollutants like cigarette smoke and $\mathrm{PM}_{2.5}$ increases ACE2 expression (1) notably in upper and lower airway epithelial cells, providing more opportunities for SARS-CoV-2 binding [2]. SARS-CoV-2 fusion glycoproteins forming the spikes require cleaving by an endogenous protease like transmembrane protease serine type 2 (TMPRSS2) in order to optimally bind to its receptor ACE2 and be internalized for replication [3]. The decreased surface expression of ACE2 limits the amount of Angiotensin II that is cleaved by ACE2 into Ang1-7. This decrease in Ang1-7 signaling through its G couple receptor MAS in favor of the pro-inflammatory $\mathrm{AngII} / \mathrm{AT}_{1} \mathrm{R}$ pathway likely contributes to COVID-19 disease pathogenesis has also been shown to increase ACE2 expression in the lungs [109]. In this mild model of lung injury, Ace2 deficiency did not exacerbate inflammation but did impair recovery from injury [109]. Ace2-deficient mice also display defective intestinal amino acid absorption and impaired intestinal barrier repair upon DSS challenge in a classic model of colitis [110]. Notably, impaired tryptophan homeostasis in Ace2-deficient mice decreases antimicrobial peptide generation resulting in an altered intestinal microbiome [110]. With ACE2 being highly expressed in enterocytes, it is therefore not surprising that intestinal infections with SARS-CoV-2 would promote gastrointestinal symptoms like diarrhea [111].

Assessing the impact of different air pollutants on ACE2 expression in a range of human cells and their role in modulation SARS-CoV-2 infections in vitro will offer valuable insights as well as provide tools to investigate mechanistic pathways shared or specific to each pollutant. Furthermore, the rapid development of a range of murine models expressing human ACE2 or SARS-CoV-2 variants that efficiently bind to murine ACE2 [112-115] will allow investigations into fundamental questions about this virus pathogenicity and identify novel disease mechanisms. Exposing these models to air pollutants like $\mathrm{PM}_{2.5}$, diesel exhaust particles, ozone, or cigarette smoke, before and/or during an infection with SARS-CoV-2, will ultimately provide mechanistic answers and highlight critical pathways involved in air pollution-mediated increased COVID-19 severity.

\section{Conclusions}

While a range of epidemiologic studies have provided support for the notion that environmental factor like air pollution contribute to COVID-19 during the first wave of the pandemic, more detailed studies conducted over the course of the whole pandemic using individualized health data and a whole range of outdoor and indoor pollutant exposures are needed to better assess to what extent air pollution did contribute to SARS-CoV-2 transmission and COVID-19 outcomes. Causality can be confirmed using animal models, which represent useful tools to investigate disease mechanisms. As age is by far the largest risk factor for severe or fatal COVID-19 [19], studying the role that lifelong exposure to air pollution has on an aging immune response [116] to viral infections should be a priority. Taken together and put into context with other socioeconomic factors, these studies should inform and promote governments facing a range of COVID-19-related challenges to adopting policies that focus on minimizing health risks and economic fallouts for vulnerable populations. Clean outdoor air conditions are community resources often not within the control of individuals. A three-pronged approach, with actions at the individual, community, and national level, may be needed to protect susceptible people from the negative health impacts of air pollution. Even if the advent of successful large-scale vaccination campaigns manages to eradicate this coronavirus, decreasing the 
impact that poor diet and air pollution has on the global burden of disease will allow us to better weather the next pandemic.

Funding This study is supported by the NIH grant R01HL132344.

\section{Declarations}

Human and Animal Rights and Informed Consent This article does not contain any studies with human or animal subjects performed by any of the authors.

Conflict of Interest The authors declare no conflicts of interest relevant to this manuscript.

\section{References}

1. Morens DM, Taubenberger JK. The mother of all pandemics is 100 years old (and going strong)! Am J Public Health. 2018;108(11):1449-54.

2. Zhang YZ, Holmes EC. A genomic perspective on the origin and emergence of SARS-CoV-2. Cell. 2020;181(2):223-7.

3. Morens DM, Fauci AS. Emerging pandemic diseases: how we got to COVID-19. Cell. 2020;182(5):1077-92.

4. University SSaECaJH. COVID-19 case tracker. https:// coronavirus.jhu.edu.

5. Guan WJ, Ni ZY, Hu Y, Liang WH, Ou CQ, He JX, et al. Clinical characteristics of coronavirus disease 2019 in China. N Engl J Med. 2020;382:1708-20.

6. Signorelli C, Odone A. Age-specific COVID-19 case-fatality rate: no evidence of changes over time. Int J Public Health. 2020;65(8): 1435-6.

7. Cunningham JW, Vaduganathan M, Claggett BL, Jering KS, Bhatt AS, Rosenthal N, et al. Clinical outcomes in young US adults hospitalized with COVID-19. JAMA Intern Med. 2020.

8. Wong LSY, Loo EXL, Kang AYH, Lau HX, Tambyah PA, Tham EH. Age-related differences in immunological responses to SARS-CoV-2. J Allergy Clin Immunol Pract. 2020;8(10):3251-8.

9. Anastassopoulou C, Gkizarioti Z, Patrinos GP, Tsakris A. Human genetic factors associated with susceptibility to SARS-CoV-2 infection and COVID-19 disease severity. Hum Genomics. 2020;14(1):40.

10. van der Made CI, Simons A, Schuurs-Hoeijmakers J, van den Heuvel G, Mantere T, Kersten S, et al. Presence of genetic variants among young men with severe COVID-19. JAMA. 2020.

11. Zhang Q, Bastard P, Liu Z, Le Pen J, Moncada-Velez M, Chen J, et al. Inborn errors of type I IFN immunity in patients with lifethreatening COVID-19. Science. 2020;370(6515).

12. Johansson H, Mersha TB, Brandt EB, Khurana Hershey GK. Interactions between environmental pollutants and genetic susceptibility in asthma risk. Curr Opin Immunol. 2019;60:156-62.

13. Murcray CE, Lewinger JP, Conti DV, Thomas DC, Gauderman WJ. Sample size requirements to detect gene-environment interactions in genome-wide association studies. Genet Epidemiol. 2011;35(3):201-10.

14. Gao YD, Ding M, Dong X, Zhang JJ, Azkur AK, Azkur D, et al. Risk factors for severe and critically ill COVID-19 patients: a review. Allergy. 2020.

15. Leung JM, Niikura M, Yang CWT, Sin DD. COVID-19 and COPD. Eur Respir J. 2020;56(2).
16. Wu Z, McGoogan JM. Characteristics of and important lessons from the coronavirus disease 2019 (COVID-19) outbreak in China: summary of a report of 72314 cases from the Chinese Center for Disease Control and Prevention. JAMA. 2020;323(13):1239-42.

17. Zhu Z, Hasegawa K, Ma B, Fujiogi M, Camargo CA Jr, Liang L. Association of asthma and its genetic predisposition with the risk of severe COVID-19. J Allergy Clin Immunol. 2020;146(2):3279 e4.

18. Skevaki C, Karsonova A, Karaulov A, Xie M, Renz H. Asthmaassociated risk for COVID-19 development. J Allergy Clin Immunol. 2020;146:1295-301.

19. Williamson EJ, Walker AJ, Bhaskaran K, Bacon S, Bates C, Morton CE, et al. Factors associated with COVID-19-related death using OpenSAFELY. Nature. 2020;584(7821):430-6.

20. Pivonello R, Auriemma RS, Pivonello C, Isidori AM, Corona G, Colao A, et al. Sex disparities in Covid-19 severity and outcome: are men weaker or women stronger? Neuroendocrinology. 2020.

21. Carethers JM. Insights into disparities observed with COVID-19. J Intern Med. 2020.

22. Brandt EB, Beck AF, Mersha TB. Air pollution, racial disparities, and COVID-19 mortality. J Allergy Clin Immunol. 2020;146(1): 61-3.

23. Webb Hooper M, Napoles AM, Perez-Stable EJ. COVID-19 and racial/ethnic disparities. JAMA. 2020;323(24):2466-7.

24. Bambra C, Riordan R, Ford J, Matthews F. The COVID-19 pandemic and health inequalities. J Epidemiol Community Health. 2020;74(11):964-8.

25. Niedzwiedz CL, O'Donnell CA, Jani BD, Demou E, Ho FK, Celis-Morales $\mathrm{C}$, et al. Ethnic and socioeconomic differences in SARS-CoV-2 infection: prospective cohort study using UK Biobank. BMC Med. 2020;18(1):160.

26. Price-Haywood EG, Burton J, Fort D, Seoane L. Hospitalization and mortality among Black patients and White patients with Covid-19. N Engl J Med. 2020;382(26):2534-43.

27. Yehia BR, Winegar A, Fogel R, Fakih M, Ottenbacher A, Jesser $\mathrm{C}$, et al. Association of race with mortality among patients hospitalized with coronavirus disease 2019 (COVID-19) at 92 US hospitals. JAMA Netw Open. 2020;3(8):e2018039.

28. Benskin LL. A basic review of the preliminary evidence that COVID-19 risk and severity is increased in vitamin D deficiency. Front Public Health. 2020;8:513.

29. Cohen AJ, Brauer M, Burnett R, Anderson HR, Frostad J, Estep $\mathrm{K}$, et al. Estimates and 25-year trends of the global burden of disease attributable to ambient air pollution: an analysis of data from the Global Burden of Diseases Study 2015. Lancet. 2017:389(10082):1907-18.

30. Landrigan PJ, Fuller R, Acosta NJR, Adeyi O, Arnold R, Basu $\mathrm{NN}$, et al. The Lancet Commission on pollution and health. Lancet. 2018;391(10119):462-512.

31. Pope CA 3rd, Coleman N, Pond ZA, Burnett RT. Fine particulate air pollution and human mortality: $25+$ years of cohort studies. Environ Res. 2020;183:108924.

32. Di Q, Wang Y, Zanobetti A, Wang Y, Koutrakis P, Choirat C, et al. Air pollution and mortality in the Medicare population. $\mathrm{N}$ Engl J Med. 2017;376(26):2513-22.

33. Tessum CW, Apte JS, Goodkind AL, Muller NZ, Mullins KA, Paolella DA, et al. Inequity in consumption of goods and services adds to racial-ethnic disparities in air pollution exposure. Proc Natl Acad Sci U S A. 2019;116(13):6001-6.

34. Steinle S, Johnston HJ, Loh M, Mueller W, Vardoulakis S, Tantrakarnapa K, et al. In utero exposure to particulate air pollution during pregnancy: impact on birth weight and health through the life course. Int J Environ Res Public Health. 2020;17(23).

35. Luyten LJ, Saenen ND, Janssen BG, Vrijens K, Plusquin M, Roels $\mathrm{HA}$, et al. Air pollution and the fetal origin of disease: a systematic 
review of the molecular signatures of air pollution exposure in human placenta. Environ Res. 2018;166:310-23.

36. Lodovici M, Bigagli E. Oxidative stress and air pollution exposure. J Toxicol. 2011;2011:487074.

37. Gauderman WJ, Urman R, Avol E, Berhane K, McConnell R, Rappaport E, et al. Association of improved air quality with lung development in children. N Engl J Med. 2015;372(10):905-13.

38. Kim D, Chen Z, Zhou LF, Huang SX. Air pollutants and early origins of respiratory diseases. Chronic Dis Transl Med. 2018;4(2):75-94.

39. Brandt EB, Myers JM, Ryan PH, Hershey GK. Air pollution and allergic diseases. Curr Opin Pediatr. 2015;27(6):724-35.

40. Adamkiewicz G, Liddie J, Gaffin JM. The respiratory risks of ambient/outdoor air pollution. Clin Chest Med. 2020;41(4):80924.

41. Domingo JL, Rovira J. Effects of air pollutants on the transmission and severity of respiratory viral infections. Environ Res. 2020;187:109650.

42. Horne BD, Joy EA, Hofmann MG, Gesteland PH, Cannon JB, Lefler JS, et al. Short-term elevation of fine particulate matter air pollution and acute lower respiratory infection. Am J Respir Crit Care Med. 2018;198(6):759-66.

43. Cui Y, Zhang ZF, Froines J, Zhao J, Wang H, Yu SZ, et al. Air pollution and case fatality of SARS in the People's Republic of China: an ecologic study. Environ Health. 2003;2(1):15.

44. Kan HD, Chen BH, Fu CW, Yu SZ, Mu LN. Relationship between ambient air pollution and daily mortality of SARS in Beijing. Biomed Environ Sci. 2005;18(1):1-4.

45. Cai QC, Lu J, Xu QF, Guo Q, Xu DZ, Sun QW, et al. Influence of meteorological factors and air pollution on the outbreak of severe acute respiratory syndrome. Public Health. 2007;121(4):258-65.

46. Villeneuve PJ, Goldberg MS. Methodological considerations for epidemiological studies of air pollution and the SARS and COVID-19 coronavirus outbreaks. Environ Health Perspect. 2020;128(9):95001.

47. Moriyama M, Hugentobler WJ, Iwasaki A. Seasonality of respiratory viral infections. Annu Rev Virol. 2020;7(1):83-101.

48. Audi A, Allbrahim M, Kaddoura M, Hijazi G, Yassine HM, Zaraket H. Seasonality of respiratory viral infections: will COVID-19 follow suit? Front Public Health. 2020;8:567184.

49. Riddell S, Goldie S, Hill A, Eagles D, Drew TW. The effect of temperature on persistence of SARS-CoV-2 on common surfaces. Virol J. 2020;17(1):145.

50. Ghosh D, Bernstein JA, Mersha TB. COVID-19 pandemic: the African paradox. J Glob Health. 2020;10(2):020348.

51. Liu J, Zhou J, Yao J, Zhang X, Li L, Xu X, et al. Impact of meteorological factors on the COVID-19 transmission: a multicity study in China. Sci Total Environ. 2020;726:138513.

52. Sarkodie SA, Owusu PA. Impact of meteorological factors on COVID-19 pandemic: evidence from top 20 countries with confirmed cases. Environ Res. 2020;191:110101.

53. Ma Y, Pei S, Shaman J, Dubrow R, Chen K. Role of air temperature and humidity in the transmission of SARS-CoV-2 in the United States. medRxiv. 2020.

54. Kulkarni H, Khandait H, Narlawar UW, Rathod P, Mamtani M. Independent association of meteorological characteristics with initial spread of Covid-19 in India. Sci Total Environ. 2020;142801.

55. Pan J, Yao Y, Liu Z, Meng X, Ji JS, Qiu Y, et al. Warmer weather unlikely to reduce the COVID-19 transmission: an ecological study in 202 locations in 8 countries. Sci Total Environ. 2021;753:142272.

56. Baker RE, Yang W, Vecchi GA, Metcalf CJE, Grenfell BT. Susceptible supply limits the role of climate in the early SARSCoV-2 pandemic. Science. 2020;369(6501):315-9.
57. Carlson CJ, Gomez ACR, Bansal S, Ryan SJ. Misconceptions about weather and seasonality must not misguide COVID-19 response. Nat Commun. 2020;11(1):4312.

58. Zaitchik BF, Sweijd N, Shumake-Guillemot J, Morse A, Gordon C, Marty A, et al. A framework for research linking weather, climate and COVID-19. Nat Commun. 2020;11(1):5730.

59. Perez IA, Garcia MA, Sanchez ML, Pardo N, Fernandez-Duque B. Key points in air pollution meteorology. Int J Environ Res Public Health. 2020;17(22).

60. Walker PGT, Whittaker C, Watson OJ, Baguelin M, Winskill P, Hamlet A, et al. The impact of COVID-19 and strategies for mitigation and suppression in low- and middle-income countries. Science. 2020;369(6502):413-22.

61. Lai S, Ruktanonchai NW, Zhou L, Prosper O, Luo W, Floyd JR, et al. Effect of non-pharmaceutical interventions to contain COVID-19 in China. Nature. 2020;585(7825):410-3.

62. Hsiang S, Allen D, Annan-Phan S, Bell K, Bolliger I, Chong T, et al. The effect of large-scale anti-contagion policies on the COVID-19 pandemic. Nature. 2020;584(7820):262-7.

63. Flaxman S, Mishra S, Gandy A, Unwin HJT, Mellan TA, Coupland $\mathrm{H}$, et al. Estimating the effects of non-pharmaceutical interventions on COVID-19 in Europe. Nature. 2020;584(7820): 257-61.

64. Le T, Wang Y, Liu L, Yang J, Yung YL, Li G, et al. Unexpected air pollution with marked emission reductions during the COVID19 outbreak in China. Science. 2020;369(6504):702-6.

65. Collivignarelli MC, Abba A, Bertanza G, Pedrazzani R, Ricciardi P, Carnevale MM. Lockdown for CoViD-2019 in Milan: what are the effects on air quality? Sci Total Environ. 2020;732:139280.

66. Zangari S, Hill DT, Charette AT, Mirowsky JE. Air quality changes in New York City during the COVID-19 pandemic. Sci Total Environ. 2020;742:140496.

67. Sicard P, De Marco A, Agathokleous E, Feng Z, Xu X, Paoletti E, et al. Amplified ozone pollution in cities during the COVID-19 lockdown. Sci Total Environ. 2020;735:139542.

68. Shen L, Zhao T, Wang H, Liu J, Bai Y, Kong S, et al. Importance of meteorology in air pollution events during the city lockdown for COVID-19 in Hubei Province. Central China. Sci Total Environ. 2020;754:142227.

69. Copat C, Cristaldi A, Fiore M, Grasso A, Zuccarello P, Signorelli SS, et al. The role of air pollution (PM and NO2) in COVID-19 spread and lethality: a systematic review. Environ Res. 2020;191: 110129.

70. Balmes JR. Do we really need another time-series study of the PM2.5-mortality association? N Engl J Med. 2019;381(8):774-6.

71. Zhu Y, Xie J, Huang F, Cao L. Association between short-term exposure to air pollution and COVID-19 infection: evidence from China. Sci Total Environ. 2020;727:138704.

72. Wang B, Liu J, Li Y, Fu S, Xu X, Li L, et al. Airborne particulate matter, population mobility and COVID-19: a multi-city study in China. BMC Public Health. 2020;20(1):1585.

73. Wu X, Nethery RC, Sabath MB, Braun D, Dominici F. Air pollution and COVID-19 mortality in the United States: strengths and limitations of an ecological regression analysis. Sci Adv. 2020;6(45).

74. Petroni M, Hill D, Younes L, Barkman L, Howard S, Howell IB, et al. Hazardous air pollutant exposure as a contributing factor to COVID-19 mortality in the United States. Environ Res Lett 2020;15(9):0940a9

75. Liang D, Shi L, Zhao J, Liu P, Sarnat JA, Gao S, et al. Urban air pollution may enhance COVID-19 case-fatality and mortality rates in the United States. Innovation (N Y). 2020;1(3):100047.

76. Travaglio M, Yu Y, Popovic R, Selley L, Leal NS, Martins LM. Links between air pollution and COVID-19 in England. Environ Pollut. 2020;268(Pt A):115859. 
77. Domingo JL, Marques M, Rovira J. Influence of airborne transmission of SARS-CoV-2 on COVID-19 pandemic. A review. Environ Res. 2020;188:109861.

78. Morawska L, Milton DK. It is time to address airborne transmission of COVID-19. Clin Infect Dis. 2020.

79. van Doremalen N, Bushmaker T, Morris DH, Holbrook MG, Gamble A, Williamson BN, et al. Aerosol and surface stability of SARS-CoV-2 as compared with SARS-CoV-1. N Engl J Med. 2020;382(16):1564-7.

80. Liu Y, Ning Z, Chen Y, Guo M, Liu Y, Gali NK, et al. Aerodynamic analysis of SARS-CoV-2 in two Wuhan hospitals. Nature. 2020;582(7813):557-60.

81. Setti L, Passarini F, De Gennaro G, Barbieri P, Perrone MG, Borelli M, et al. SARS-Cov-2RNA found on particulate matter of Bergamo in Northern Italy: first evidence. Environ Res. 2020;188:109754.

82. Chirizzi D, Conte M, Feltracco M, Dinoi A, Gregoris E, Barbaro E, et al. SARS-CoV-2 concentrations and virus-laden aerosol size distributions in outdoor air in north and south of Italy. Environ Int. 2020;146:106255.

83. Paciencia I, Madureira J, Rufo J, Moreira A, Fernandes EO. A systematic review of evidence and implications of spatial and seasonal variations of volatile organic compounds (VOC) in indoor human environments. J Toxicol Environ Health B Crit Rev. 2016;19(2):47-64.

84. McDonald BC, de Gouw JA, Gilman JB, Jathar SH, Akherati A, Cappa $\mathrm{CD}$, et al. Volatile chemical products emerging as largest petrochemical source of urban organic emissions. Science. 2018;359(6377):760-4.

85. Gordon SB, Bruce NG, Grigg J, Hibberd PL, Kurmi OP, Lam KB, et al. Respiratory risks from household air pollution in low and middle income countries. Lancet Respir Med. 2014;2(10):823-60.

86. Raju S, Siddharthan T, McCormack MC. Indoor air pollution and respiratory health. Clin Chest Med. 2020;41(4):825-43.

87. Assad NA, Balmes J, Mehta S, Cheema U, Sood A. Chronic obstructive pulmonary disease secondary to household air pollution. Semin Respir Crit Care Med. 2015;36(3):408-21.

88. Amaral AFS, Patel J, Kato BS, Obaseki DO, Lawin H, Tan WC, et al. Airflow obstruction and use of solid fuels for cooking or heating: BOLD results. Am J Respir Crit Care Med. 2018;197(5):595-610.

89. Thakur M, Boudewijns EA, Babu GR, van Schayck OCP. Biomass use and COVID-19: a novel concern. Environ Res. 2020;186:109586.

90. Gallus S, Lugo A, Gorini G. No double-edged sword and no doubt about the relation between smoking and COVID-19 severity. Eur J Intern Med. 2020;77:33-5.

91. Lippi G, Sanchis-Gomar F, Henry BM. Active smoking and COVID-19: a double-edged sword. Eur J Intern Med. 2020;77: $123-4$.

92. Jary H, Simpson H, Havens D, Manda G, Pope D, Bruce N, et al. Household air pollution and acute lower respiratory infections in adults: a systematic review. PLoS One. 2016;11(12):e0167656.

93. Bind MA. Causal modeling in environmental health. Annu Rev Public Health. 2019;40:23-43.

94. Griffith GJ, Morris TT, Tudball MJ, Herbert A, Mancano G, Pike $\mathrm{L}$, et al. Collider bias undermines our understanding of COVID-19 disease risk and severity. Nat Commun. 2020;11(1):5749.

95. Wu X, Braun D, Schwartz J, Kioumourtzoglou MA, Dominici F. Evaluating the impact of long-term exposure to fine particulate matter on mortality among the elderly. Sci Adv. 2020;6(29): eaba5692.
96. Brokamp C, Brandt EB, Ryan PH. Assessing exposure to outdoor air pollution for epidemiological studies: model-based and personal sampling strategies. J Allergy Clin Immunol. 2019;143(6): 2002-6.

97. Mishra T, Wang M, Metwally AA, Bogu GK, Brooks AW, Bahmani A, et al. Pre-symptomatic detection of COVID-19 from smartwatch data. Nat Biomed Eng. 2020;4(12):1208-20.

98. Li W, Moore MJ, Vasilieva N, Sui J, Wong SK, Berne MA, et al. Angiotensin-converting enzyme 2 is a functional receptor for the SARS coronavirus. Nature. 2003;426(6965):450-4.

99. Wrapp D, Wang N, Corbett KS, Goldsmith JA, Hsieh CL, Abiona O, et al. Cryo-EM structure of the 2019-nCoV spike in the prefusion conformation. Science. 2020;367(6483):1260-3.

100. Hoffmann M, Kleine-Weber H, Schroeder S, Kruger N, Herrler T, Erichsen S, et al. SARS-CoV-2 cell entry depends on ACE2 and TMPRSS2 and is blocked by a clinically proven protease inhibitor. Cell. 2020;181(2):271-80 e8.

101. Yao Y, Wang H, Liu Z. Expression of ACE2 in airways: implication for COVID-19 risk and disease management in patients with chronic inflammatory respiratory diseases. Clin Exp Allergy. 2020;50:1313-24.

102. Gheblawi M, Wang K, Viveiros A, Nguyen Q, Zhong JC, Turner $\mathrm{AJ}$, et al. Angiotensin-converting enzyme 2: SARS-CoV-2 receptor and regulator of the renin-angiotensin system: celebrating the 20th anniversary of the discovery of ACE2. Circ Res. 2020;126(10):1456-74.

103. Samavati L, Uhal BD. ACE2, Much more than just a receptor for SARS-COV-2. Front Cell Infect Microbiol. 2020;10:317.

104. Imai Y, Kuba K, Rao S, Huan Y, Guo F, Guan B, et al. Angiotensin-converting enzyme 2 protects from severe acute lung failure. Nature. 2005;436(7047):112-6.

105. Kuba K, Imai Y, Rao S, Gao H, Guo F, Guan B, et al. A crucial role of angiotensin converting enzyme 2 (ACE2) in SARS coronavirus-induced lung injury. Nat Med. 2005;11(8):875-9.

106. Zhang H, Rostami MR, Leopold PL, Mezey JG, O'Beirne SL, Strulovici-Barel Y, et al. Expression of the SARS-CoV-2 ACE2 receptor in the human airway epithelium. Am J Respir Crit Care Med. 2020;202(2):219-229.

107. Radzikowska U, Ding M, Tan G, Zhakparov D, Peng Y, Wawrzyniak P, et al. Distribution of ACE2, CD147, CD26, and other SARS-CoV-2 associated molecules in tissues and immune cells in health and in asthma, COPD, obesity, hypertension, and COVID-19 risk factors. Allergy. 2020;75(11):2829-45.

108. Leung JM, Yang CX, Tam A, Shaipanich T, Hackett TL, Singhera GK, et al. ACE-2 expression in the small airway epithelia of smokers and COPD patients: implications for COVID-19. Eur Respir J. 2020;55(5).

109. Lin CI, Tsai CH, Sun YL, Hsieh WY, Lin YC, Chen CY, et al. Instillation of particulate matter 2.5 induced acute lung injury and attenuated the injury recovery in ACE2 knockout mice. Int J Biol Sci. 2018;14(3):253-65.

110. Hashimoto T, Perlot T, Rehman A, Trichereau J, Ishiguro H, Paolino $\mathrm{M}$, et al. ACE2 links amino acid malnutrition to microbial ecology and intestinal inflammation. Nature. 2012;487(7408):477-81.

111. Syed A, Khan A, Gosai F, Asif A, Dhillon S. Gastrointestinal pathophysiology of SARS-CoV2 - a literature review. J Community Hosp Intern Med Perspect. 2020;10(6):523-8.

112. Dinnon KH 3rd, Leist SR, Schafer A, Edwards CE, Martinez DR, Montgomery SA, et al. A mouse-adapted model of SARS-CoV-2 to test COVID-19 countermeasures. Nature. 2020;586(7830): $560-6$. 
113. Sun J, Zhuang Z, Zheng J, Li K, Wong RL, Liu D, et al. Generation of a broadly useful model for COVID-19 pathogenesis, vaccination, and treatment. Cell. 2020;182(3):734-43 e5.

114. Jiang RD, Liu MQ, Chen Y, Shan C, Zhou YW, Shen XR, et al. Pathogenesis of SARS-CoV-2 in transgenic mice expressing human angiotensin-converting enzyme 2. Cell. 2020;182(1):50-8 e8.

115. Gu H, Chen Q, Yang G, He L, Fan H, Deng YQ, et al. Adaptation of SARS-CoV-2 in BALB/c mice for testing vaccine efficacy. Science. 2020;369(6511):1603-7.
116. Akbar AN, Gilroy DW. Aging immunity may exacerbate COVID19. Science. 2020;369(6501):256-7.

Publisher's Note Springer Nature remains neutral with regard to jurisdictional claims in published maps and institutional affiliations. 